\title{
A Novel Power Electronic Inverter Circuit for Transformerless Photovoltaic Systems
}

\author{
Cao Hai-Yan \\ Department of Information Engineering, Shijiazhuang University of Economics, Shijiazhuang 050031, China \\ Correspondence should be addressed to Cao Hai-Yan; beatles888@126.com
}

Received 8 February 2014; Revised 5 May 2014; Accepted 5 May 2014; Published 26 May 2014

Academic Editor: Gerard Ghibaudo

Copyright (C) 2014 Cao Hai-Yan. This is an open access article distributed under the Creative Commons Attribution License, which permits unrestricted use, distribution, and reproduction in any medium, provided the original work is properly cited.

Capacitive leakage current is one of the most important issues for transformerless photovoltaic systems. In order to deal with the capacitive leakage current, a new power electronic inverter circuit is proposed in this paper. The inverter circuit consists of six switches and operates with constant common mode voltage. Theoretical analysis is conducted to clarify the circuit operation principle and the common mode characteristic. The performance evaluation test is carried out, and test results demonstrate that the capacitive leakage current can be significantly minimized with the proposed power electronic inverter circuit.

\section{Introduction}

Photovoltaic (PV) power systems are very attractive and widely used in recent years. In order to integrate the PV systems into grid, a power electronic component should be required to convert DC energy source generated by PV arrays to AC component [1], which is fed into grid. In general, a transformer is installed between PV arrays and grid for galvanic isolation. The transformer is heavy with large volume, along with the copper and iron losses during transformer operation $[2,3]$. Therefore, the transformerless PV system is popular and received more and more attention [4-12], due to its low cost, small size, and high efficiency. However, a technical challenge arises for transformerless PV systems. More specifically, the capacitive leakage current is generated between photovoltaic modules and the ground [13]. In practice, this capacitive leakage current is very difficult to handle, because the capacitance between photovoltaic modules and ground is usually highly unpredictable, and it varies significantly with temperature or humidity [14]. The presence of leakage currents is very harmful, since they could put the life of a photovoltaic module installer at risk if he touches the photovoltaic module [15]. Additionally, they will bring high-frequency harmonics, which may lead to problems with electromagnetic compatibility [16]. Therefore, it is important to deal with the capacitive leakage current problem in the transformerless PV system.

The objective of this paper is to present a novel power electronic inverter circuit for transformerless photovoltaic system. The capacitive leakage current can be minimized with the proposed inverter circuit.

\section{Circuit Description}

The schematic diagram of the proposed power electronic inverter circuit is illustrated in Figure 1. It should be noted that the parasitic capacitance between ground and positive terminal of $\mathrm{dc}$ bus point is one of the factors for the system stray capacitance. In this case, considering the entire stray capacitances of $C_{\mathrm{pv}}$, the parasitic capacitance between ground and positive terminal of the inverter $\mathrm{dc}$ bus point will be $C_{\mathrm{pv}} / 2$ and so is the capacitance of ground-negative terminal, as shown in Figure 1. The capacitance value depends on the PV panel frame structure, weather conditions, humidity, and so on. Therefore, it is usually highly unpredictable. In order to clarify the capacitive leakage current minimization 
TABLE 1: Operation modes and voltages.

\begin{tabular}{|c|c|c|c|c|c|c|c|c|c|}
\hline & $S_{1}$ & $S_{2}$ & $S_{3}$ & $S_{4}$ & $S_{5}$ & $S_{6}$ & $U_{\text {an }}$ & $U_{\mathrm{bn}}$ & $U_{\mathrm{cm}}$ \\
\hline Mode 1 & 1 & 0 & 0 & 1 & 0 & 1 & $V_{d}$ & 0 & $V_{d} / 2$ \\
\hline Mode 2 & 0 & 0 & 0 & 0 & 0 & 1 & $V_{d} / 2$ & $V_{d} / 2$ & $V_{d} / 2$ \\
\hline Mode 3 & 0 & 1 & 1 & 0 & 1 & 0 & 0 & $V_{d}$ & $V_{d} / 2$ \\
\hline Mode 4 & 0 & 1 & 0 & 0 & 0 & 0 & $V_{d} / 2$ & $V_{d} / 2$ & $V_{d} / 2$ \\
\hline
\end{tabular}

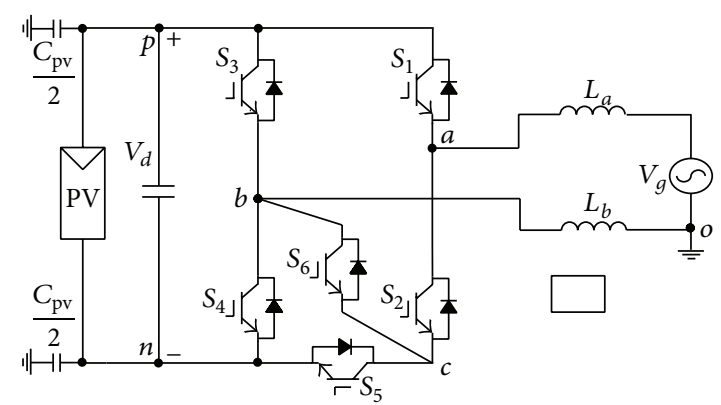

FIGURE 1: Schematic diagram of proposed power electronic inverter circuit.

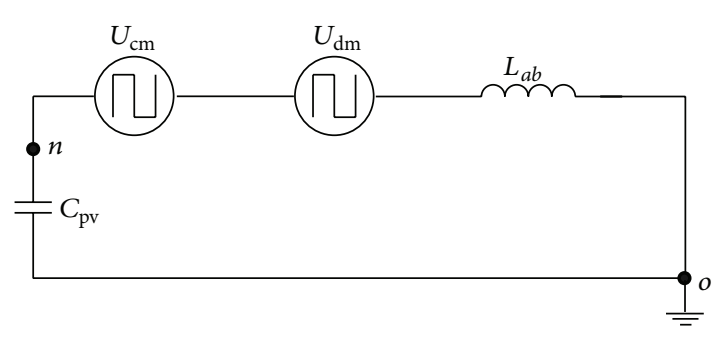

FIGURE 2: System's common mode model [17].

mechanism, the system's common mode model is built, as shown in Figure 2, where $U_{\mathrm{cm}}$ is the common mode voltage and $U_{\mathrm{dm}}$ is defined as follows:

$$
\begin{gathered}
U_{\mathrm{cm}}=\frac{U_{\mathrm{an}}+U_{\mathrm{bn}}}{2}, \\
U_{\mathrm{dm}}=\frac{U_{a b}\left(L_{a}-L_{b}\right)}{2\left(L_{a}+L_{b}\right)}, \\
L_{a b}=\frac{L_{a} L_{b}}{L_{a}+L_{b}} .
\end{gathered}
$$

In practice, the filter inductors $L_{a}$ and $L_{b}$ are designed with the equal value; that is, $L_{a}=L_{b}$. So, the differential mode voltage $U_{a b}$ does not contribute to the capacitive leakage current, as shown in (2) and Figure 2.

On the other hand, if the common mode voltage $U_{\mathrm{cm}}$ is time varying, the capacitive leakage current will arise and flow in the loop, as shown in Figure 2.

In order to deal with the capacitive leakage current, it is of great importance that the common mode voltage $U_{\mathrm{cm}}$ in Figure 2 should be kept constant. The following will present this objective achieved by the proposed power electronic inverter circuit.
The proposed inverter circuit operates in four modes, as shown in Figure 4 and Table 1.

In Mode 1 , the switches $S_{1}, S_{4}$, and $S_{6}$ are turned on, and other switches are turned off. The differential mode voltage $U_{a b}$ is $V_{d}$, while the common mode voltage can be expressed as

$$
U_{\mathrm{cm}}=\frac{1}{2}\left(U_{\mathrm{an}}+U_{\mathrm{bn}}\right)=\frac{1}{2}\left(V_{d}+0\right)=\frac{V_{d}}{2} .
$$

In Mode 2, only the switch $S_{6}$ is turned on, and other switches are turned off. The current flows through $S_{6}$ and diode of $S_{2}$. In this case, the differential mode voltage $U_{a b}$ is 0 , while the common mode voltage remains unchanged as

$$
U_{\mathrm{cm}}=\frac{1}{2}\left(U_{\mathrm{an}}+U_{\mathrm{bn}}\right)=\frac{1}{2}\left(\frac{V_{d}}{2}+\frac{V_{d}}{2}\right)=\frac{V_{d}}{2} .
$$

In Mode 3, the switches $S_{2}, S_{3}$, and $S_{5}$ are turned on, and other switches are turned off. The differential mode voltage $U_{a b}$ is $-V_{d}$, while the common mode voltage can be expressed as

$$
U_{\mathrm{cm}}=\frac{1}{2}\left(U_{\mathrm{an}}+U_{\mathrm{bn}}\right)=\frac{1}{2}\left(0+V_{d}\right)=\frac{V_{d}}{2} .
$$

In Mode 4, only the switch $S_{2}$ is turned on, and other switches are turned off. The current flows through $S_{2}$ and diode of $S_{6}$. In this case, the differential mode voltage $U_{a b}$ is 0 , while the common mode voltage $U_{\mathrm{cm}}$ remains unchanged as

$$
U_{\mathrm{cm}}=\frac{1}{2}\left(U_{\mathrm{an}}+U_{\mathrm{bn}}\right)=\frac{1}{2}\left(\frac{V_{d}}{2}+\frac{V_{d}}{2}\right)=\frac{V_{d}}{2} .
$$

In summary, the above analysis reveals that the common mode voltage can be kept constant as $V_{d} / 2$ all the time. Therefore, the capacitive leakage current can be significantly minimized, according to theoretical analysis of Figure 2. The following will present the test results. 


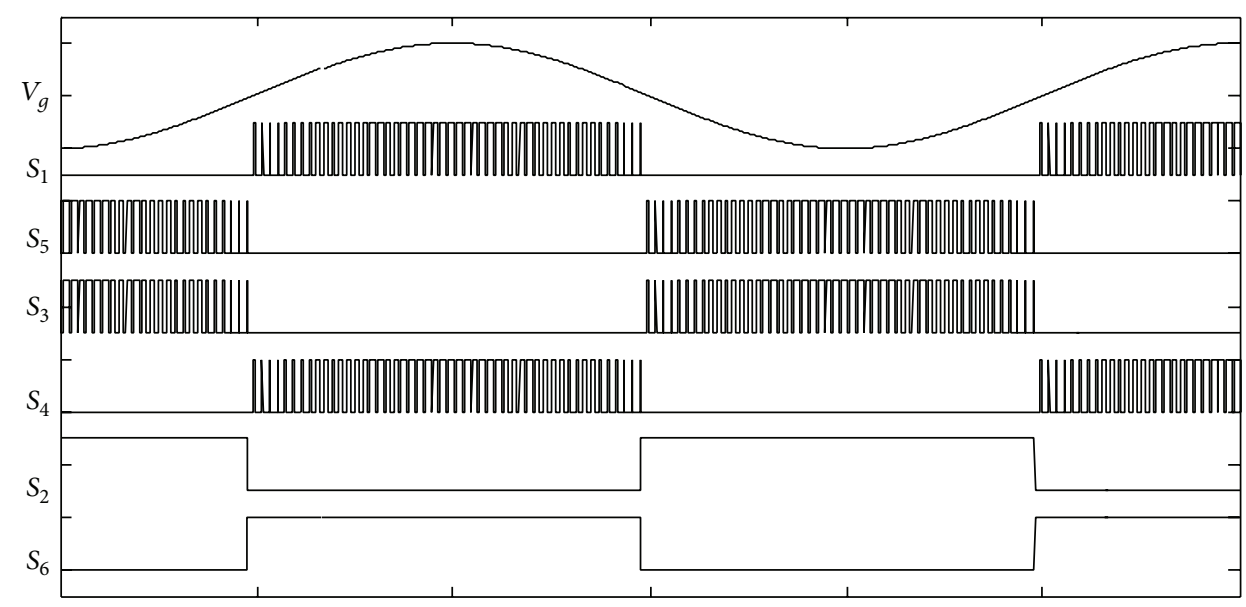

FIGURE 3: Switching state of the proposed inverter circuit.

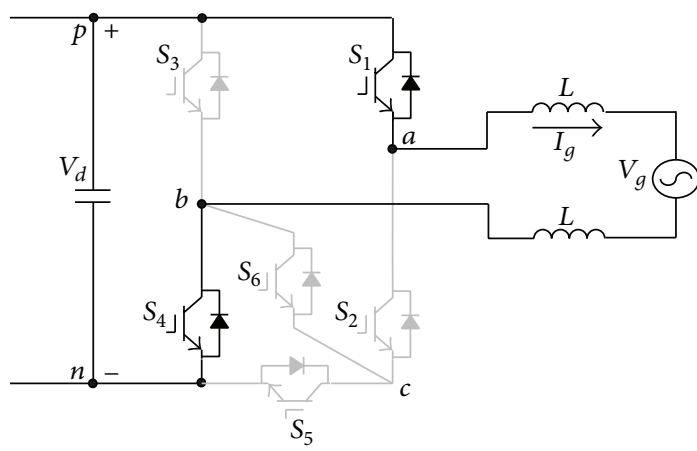

(a) Mode 1

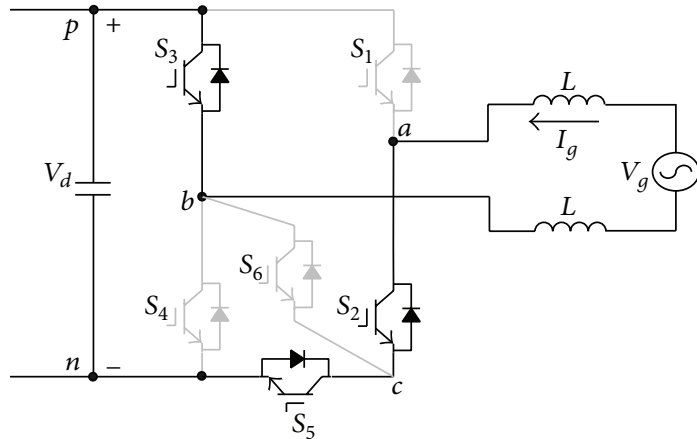

(c) Mode 3

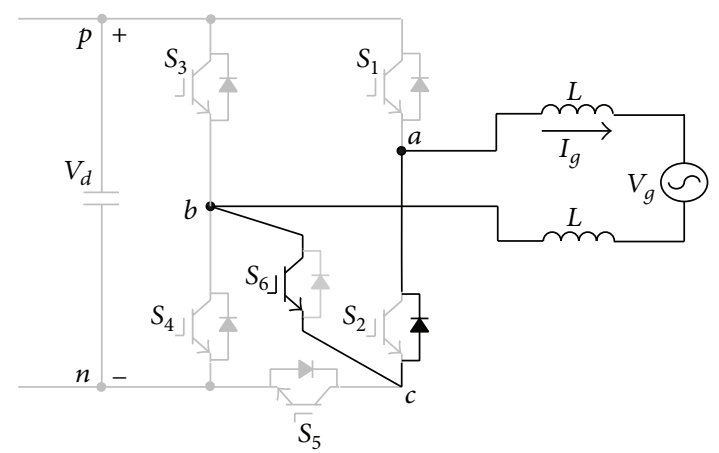

(b) Mode 2

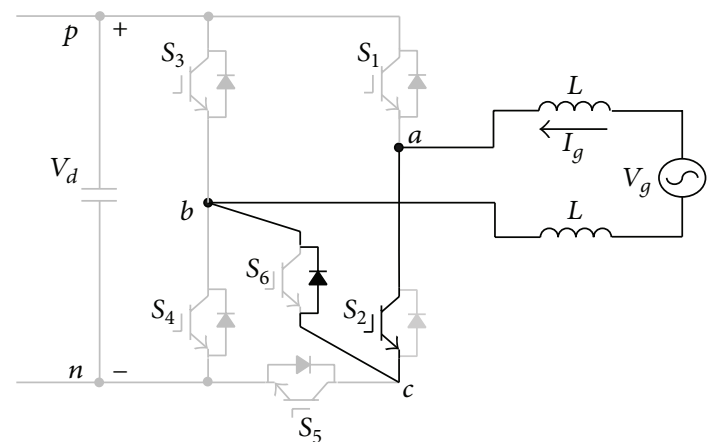

(d) Mode 4

FIGURE 4: Operation modes of the proposed inverter.

\section{Performance Evaluation}

In order to verify the effectiveness of the proposed power electronic inverter circuit, the inverter circuit is designed in MATLAB/Simulink. The circuit components and parameters are listed as follows: system power is $3 \mathrm{~kW}$, dc bus voltage $V_{d}$ is $400 \mathrm{~V}$, grid voltage $V_{g}$ is $220 \mathrm{Vac}$, grid frequency is $50 \mathrm{~Hz}$, inverter circuit switching frequency is $10 \mathrm{kHz}$, circuit filter inductor $L_{a}=L_{b}=3 \mathrm{mH}$, and parasitic capacitor $C_{\mathrm{PV}}=$ $100 \mathrm{nF}$; see Figure 3.

Figure 5(a) shows the test waveform of the switch states; it can be observed that, at any given time, only two switches operate in high-frequency mode and the other four switches operate in low-frequency mode, so the high efficiency can be achieved. On the other hand, the inverter output voltage waveform is shown in Figure 5(b), where three-level output 


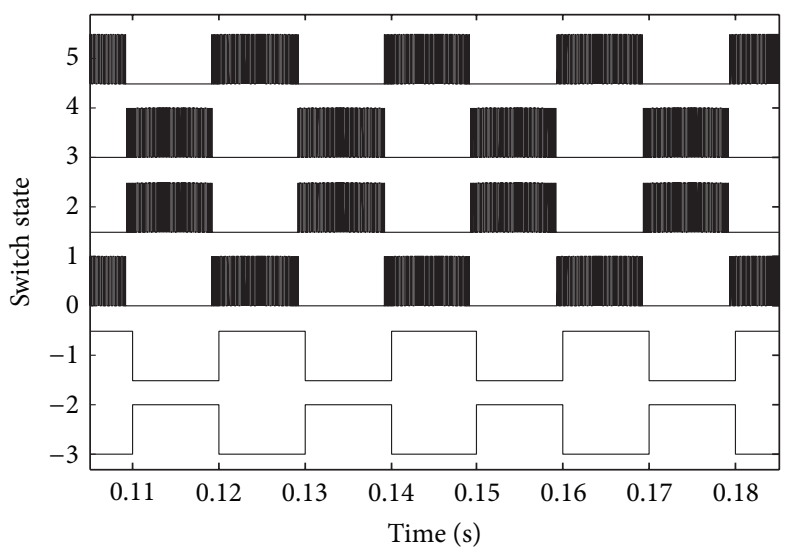

(a) Switch states (from bottom to top: $S_{6}, S_{2}, S_{4}, S_{3}, S_{5}$, and $S_{1}$ )
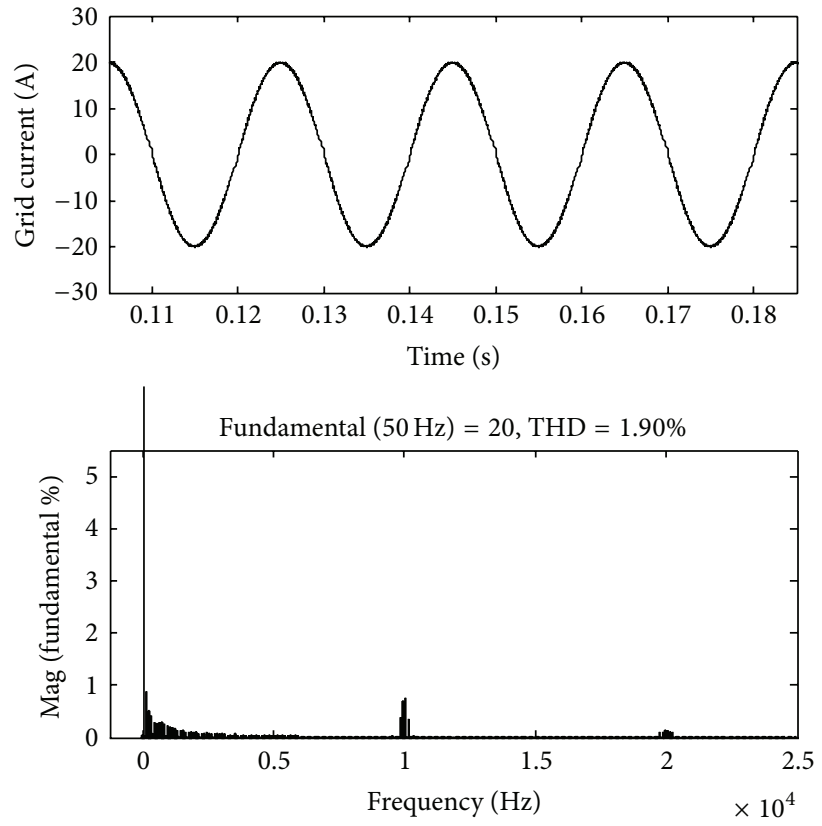

(c) Grid current and spectrum

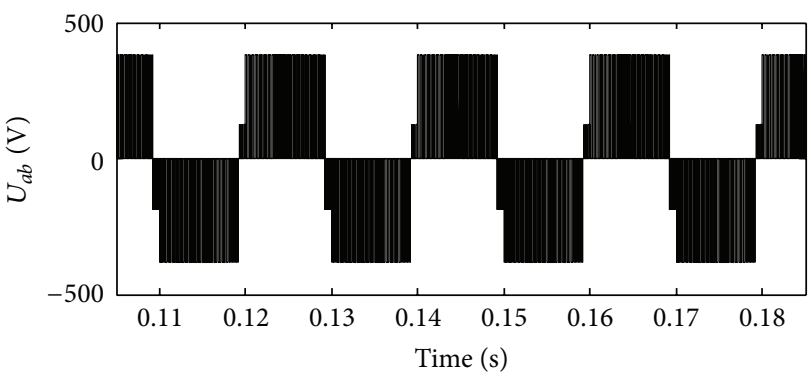

(b) Inverter output voltage $U_{a b}$
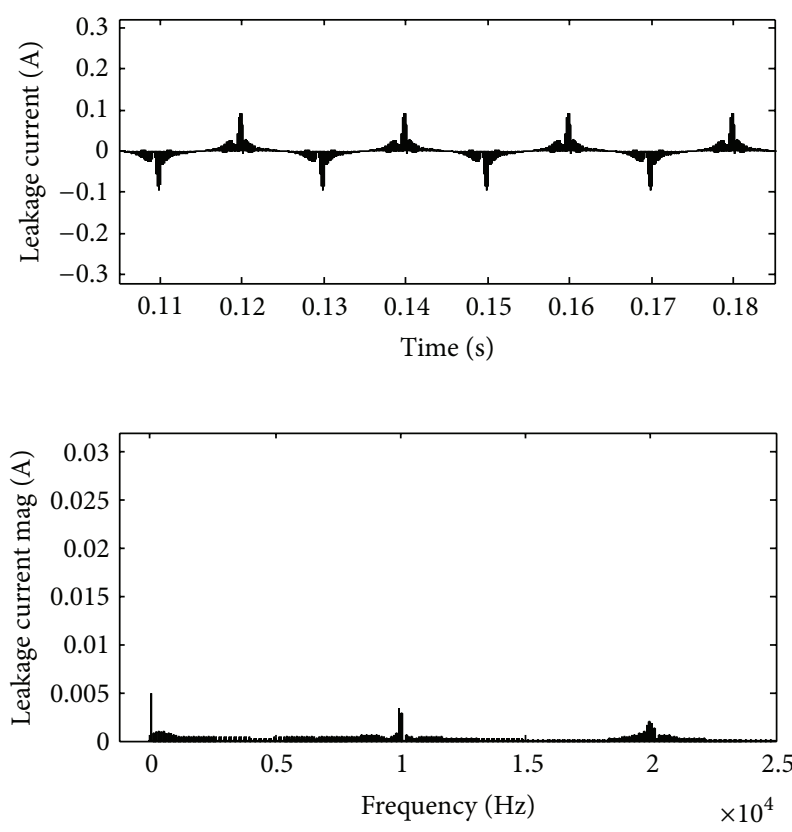

(d) Capacitive leakage current and spectrum

FIgURE 5: Test results.

voltage is achieved. It is beneficial to the grid current ripple reduction. Figure 5(c) shows the grid current waveform and its spectrum analysis. It can be seen that the grid current is sinusoidal with the total harmonic distortion of $1.9 \%$, which is well below 5\% specified in IEEE Std. 929-2000 [18].

Figure 5(d) shows the capacitive leakage current waveform and its spectrum analysis. It can be seen that the leakage current is well below $300 \mathrm{~mA}$ specified in VDE 0126-1-1, thanks to the proposed power electronic inverter.

\section{Conclusion}

This paper has presented a new power electronic inverter circuit. Its unique feature lies in that the proposed circuit can keep the system's common mode voltage constant all the time, and thus the capacitive leakage current can be significantly minimized, which complies with the international standard
IEEE Std. 929-2000 and VDE 0126-1-1. Therefore, it is attractive to the transformerless photovoltaic system applications. It should be noted that other different inverter circuits are also interesting and can be used for the transformerless photovoltaic system applications; please refer to $[19,20]$ for further reading.

\section{Conflict of Interests}

The author declares that there is no conflict of interests regarding the publication of this paper.

\section{References}

[1] S. B. Kjaer, J. K. Pedersen, and F. Blaabjerg, "A review of singlephase grid-connected inverters for photovoltaic modules," IEEE 
Transactions on Industry Applications, vol. 41, no. 5, pp. 12921306, 2005.

[2] M. Armstrong, D. J. Atkinson, C. M. Johnson, and T. D. Abeyasekera, "Auto-calibrating dc link current sensing technique for transformerless, grid connected, H-bridge inverter systems," IEEE Transactions on Power Electronics, vol. 21, no. 5, pp. 1385-1393, 2006.

[3] W. M. Blewitt, D. J. Atkinson, J. Kelly, and R. A. Lakin, "Approach to low-cost prevention of DC injection in transformerless grid connected inverters," IET Power Electronics, vol. 3, no. 1, pp. 111-119, 2010.

[4] R. González, J. López, P. Sanchis, and L. Marroyo, "Transformerless inverter for single-phase photovoltaic systems," IEEE Transactions on Power Electronics, vol. 22, no. 2, pp. 693-697, 2007.

[5] Ó. López, F. D. Freijedo, A. G. Yepes et al., "Eliminating ground current in a transformerless photovoltaic application," IEEE Transactions on Energy Conversion, vol. 25, no. 1, pp. 140-147, 2010.

[6] H. Xiao, S. Xie, Y. Chen, and R. Huang, "An optimized transformerless photovoltaic grid-connected inverter," IEEE Transactions on Industrial Electronics, vol. 58, no. 5, pp. 18871895, 2011.

[7] R. González, E. Gubía, J. López, and L. Marroyo, "Transformerless single-phase multilevel-based photovoltaic inverter," IEEE Transactions on Industrial Electronics, vol. 55, no. 7, pp. 26942702, 2008

[8] H. Xiao and S. Xie, "Transformerless split-inductor neutral point clamped three-level PV grid-connected inverter," IEEE Transactions on Power Electronics, vol. 27, no. 4, pp. 1799-1808, 2012.

[9] M. C. Cavalcanti, K. C. de Oliveira, A. M. de Farias, F. A. S. Neves, G. M. S. Azevedo, and F. C. Camboim, "Modulation techniques to eliminate leakage currents in transformerless threephase photovoltaic systems," IEEE Transactions on Industrial Electronics, vol. 57, no. 4, pp. 1360-1368, 2010.

[10] S. V. Araújo, P. Zacharias, and R. Mallwitz, "Highly efficient single-phase transformerless inverters for grid-connected photovoltaic systems," IEEE Transactions on Industrial Electronics, vol. 57, no. 9, pp. 3118-3128, 2010.

[11] T. Kerekes, R. Teodorescu, P. Rodríguez, G. Vázquez, and E. Aldabas, "A new high-efficiency single-phase transformerless PV inverter topology," IEEE Transactions on Industrial Electronics, vol. 58, no. 1, pp. 184-191, 2011.

[12] W. Yu, J.-S. Lai, H. Qian, and C. Hutchens, "High-efficiency MOSFET inverter with H6-type configuration for photovoltaic nonisolated AC-module applications," IEEE Transactions on Power Electronics, vol. 26, no. 4, pp. 1253-1260, 2011.

[13] E. Gubía, P. Sanchis, A. Ursúa, J. López, and L. Marroyo, "Ground currents in single-phase transformerless photovoltaic systems," Progress in Photovoltaics: Research and Applications, vol. 15, no. 7, pp. 629-650, 2007.

[14] T. Kerekes, R. Teodorescu, M. Liserre, C. Klumpner, and M. Sumner, "Evaluation of three-phase transformerless photovoltaic inverter topologies," IEEE Transactions on Power Electronics, vol. 24, no. 9, pp. 2202-2211, 2009.

[15] J. C. Hernández, P. G. Vidal, and A. Medina, "Characterization of the insulation and leakage currents of PV generators: relevance for human safety," Renewable Energy, vol. 35, no. 3, pp. 593-601, 2010.

[16] R. Araneo, S. Lammens, M. Grossi, and S. Bertone, "EMC issues in high-power grid-connected photovoltaic plants," IEEE
Transactions on Electromagnetic Compatibility, vol. 51, no. 3, pp. 639-648, 2009.

[17] B. Yang, W. Li, Y. Gu, W. Cui, and X. He, "Improved transformerless inverter with common-mode leakage current elimination for a photovoltaic grid-connected power system," IEEE Transactions on Power Electronics, vol. 27, no. 2, pp. 752-762, 2012.

[18] IEEE Std 929, "Recommended practice for utility interface of photovoltaic systems," in Proceedings of the IEEE Standards Coordinating Committee 21 on Photovoltaics, Dispersed Generation, and Energy Storage, New York, NY, USA, 2000.

[19] Z. Li, S. Kai, X. Yan, and X. Mu, "H6 transformerless full-bridge PV grid-tied inverters," IEEE Transactions on Power Electron, vol. 29, no. 3, pp. 1229-1238, 2014.

[20] L. Zhang, K. Sun, L. Feng, Y. Xing, and M. Xu, "H6 nonisolated full bridge grid-connected PV inverters with low leakage currents," Proceedings of the Chinese Society of Electrical Engineering, vol. 32, no. 15, pp. 1-7, 2012. 

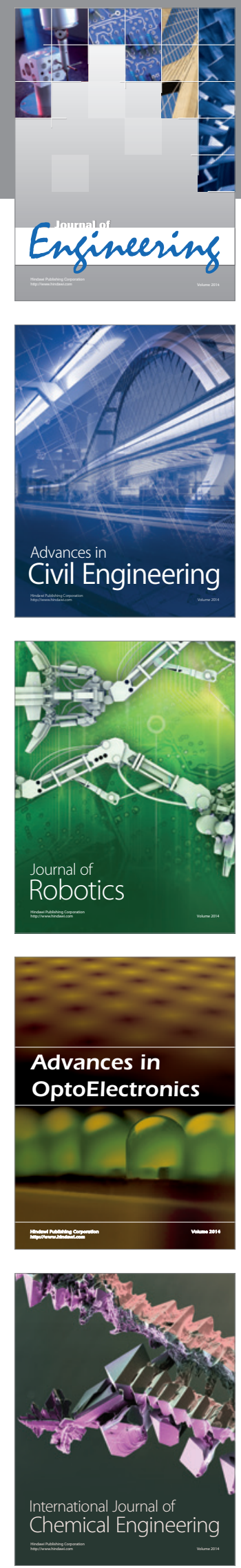

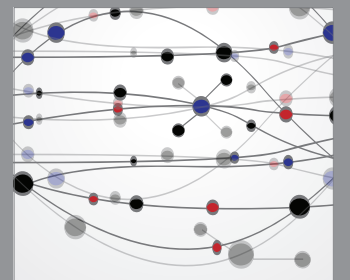

The Scientific World Journal
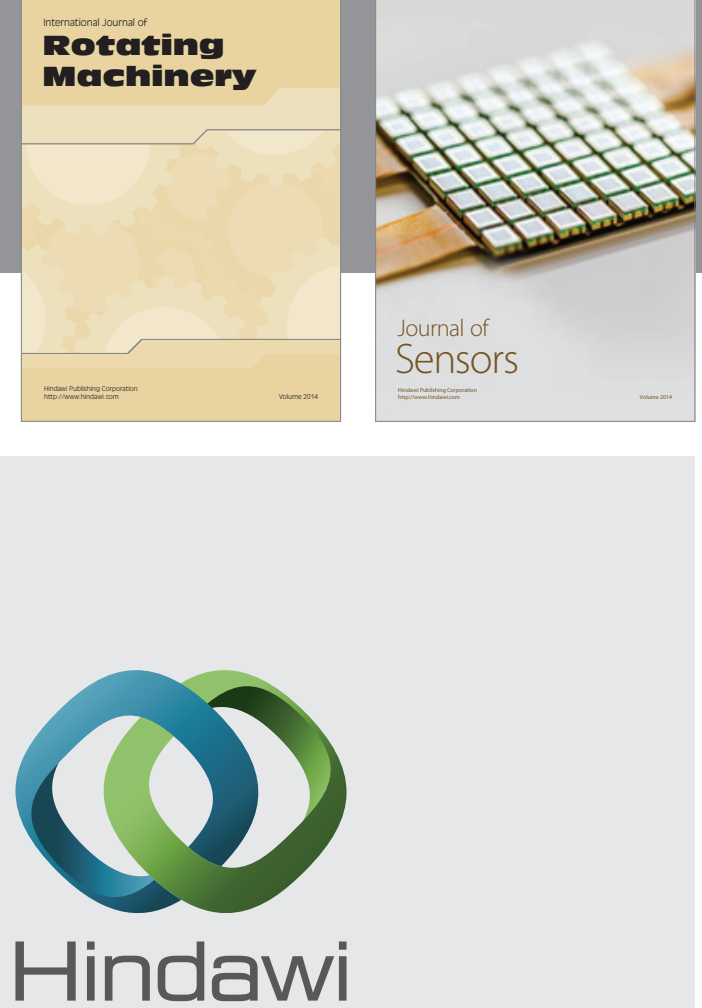

Submit your manuscripts at http://www.hindawi.com
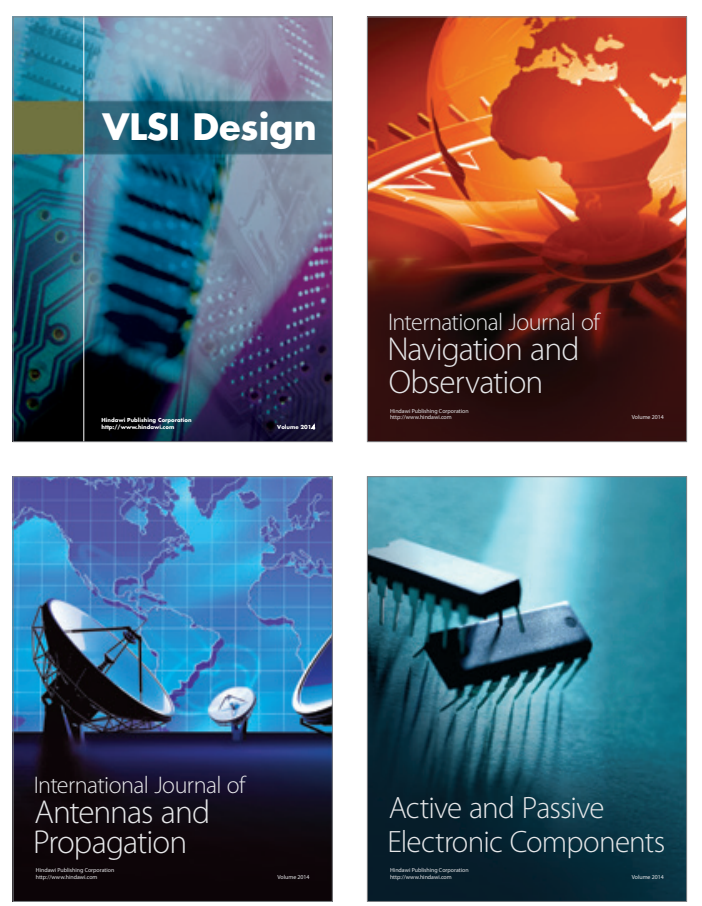
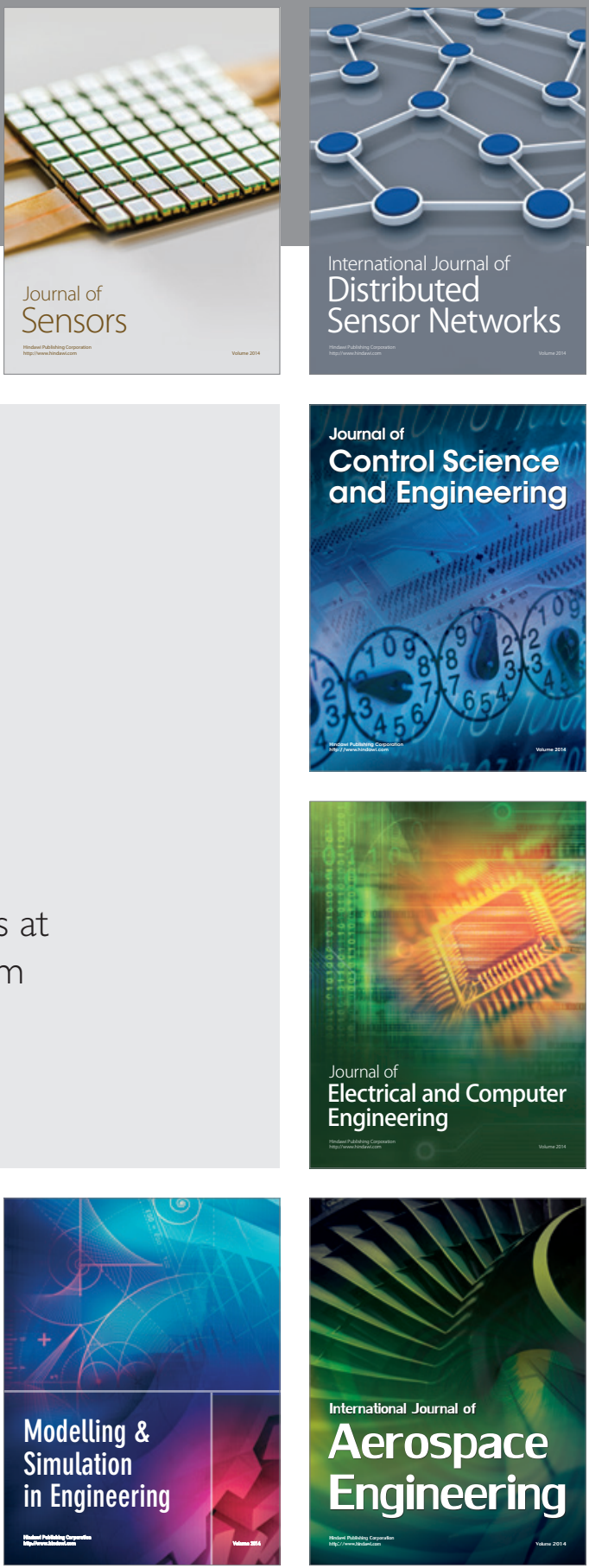

Journal of

Control Science

and Engineering
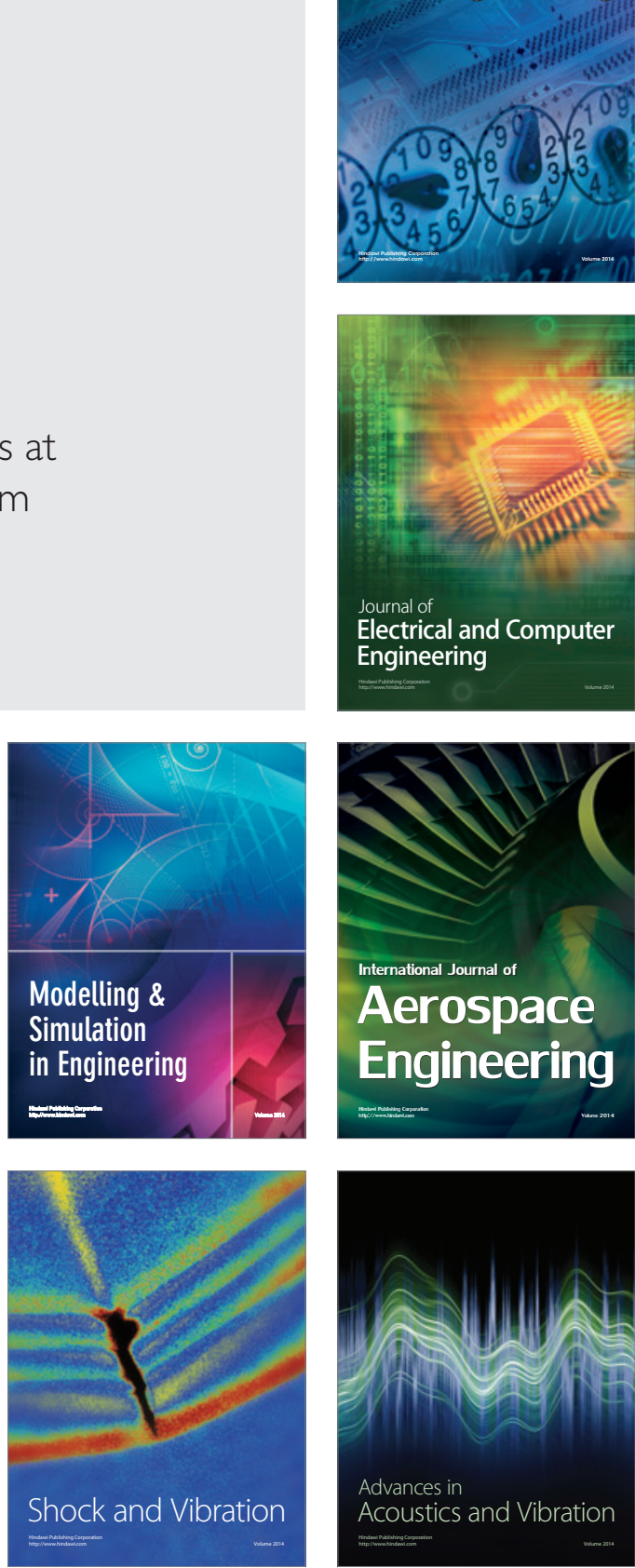